This is a post print version of an article. Published in Minerva A Review of Science, Learning and Policy, vol. 55, no. 3, pp. 371-390 2017. The final publication is available at Springer via http://dx.doi.org/10.1007/s11024-017-9318-0.

Title

\title{
The gender perspective in nursing research: A theoretical treasure chest or a 'thom' in the
} side?

\section{Authors: Pia Vuolanto and Anne Laiho}

Pia Vuolanto: Research Centre for Knowledge, Science, Technology and Innovation Studies University of Tampere Finland

Anne Laiho: Department of Education, Centre for Research on Lifelong Learning and Education University of Turku Finland

\begin{abstract}
This article contributes to the current discussion on interdisciplinarity in the health research field. It focuses on the relationship between nursing research and gender research. Nursing research is a health sciences' field which draws from the social sciences, the humanities, and biomedicine. Previous research shows the difficulties that social scientists face in their efforts to integrate with biomedical scientists. The aim of this article is to analyse nursing researchers' views about one potential collaboration partner in the social sciences and humanities: gender research.

The study draws its theoretical insights from research within the sociology of science. It uses ideas about the intertwining of power and knowledge, which is especially emphasised in the works of Pierre Bourdieu. The research material consists of 180 abstracts of nursing research articles that argue in some way about the relationship between nursing research and gender research. The Scopus database was selected because it covers nursing research in a broad sense. The scope (28 years) of the study is long. The close reading of abstracts is inspired by rhetorical discourse analysis.

We found three clearly different but also overlapping discourses that justified gender perspectives in nursing research: $G$ ender research helps to highlight the socio-political ontext in nursing research; $G$ ender research develops or reforms nursing research tradition; and $\mathrm{G}$ ender research ex ists as a form of critique within nursing research. Most of the nursing research abstracts regard gender research positively for both external and internal reasons. The abstracts also demonstrate the tensions in the relationship and discuss the views and reasons that generate scepticism towards gender research in nursing research.
\end{abstract}

\section{Keywords}

G ender research, Bourdieu, interdisciplinarity, nursing research, social sciences, sociology of science 


\section{The gender perspective in nursing research: A theoretical treasure chest or a 'thom' in the side?}

\section{Introduction}

Research into interdisciplinarity in the health research field has recently shown the difficulties that social scientists face in their efforts to integrate with biomedical scientists. For the social scientists, entering the medical field has been a 'challenging experience, as their research practices and views of academic excellence have collided with those of medicine' (Albert et al. 2015, 2009, 2008). Social scientists have reportedly met with misunderstandings between their research approach and that of biomedicine. Social scientists have been treated as 'guests' rather than as fully accepted collaborators (Prainsack et al. 2010; see also Segal 2007). This article presents a case study of the integration of the social sciences and humanities into a less studied domain of health research - that is, nursing research. We analyse nursing researchers' views about one potential collaboration partner in the social sciences and humanities: gender research. We use the term 'nursing research' throughout the article because it captures the international context of the research articles under study here. To use terms such as 'nursing science' or 'academic nursing' would be more debatable and more tied to certain national contexts such as that of Finland, where the research community refers to itself using the term 'nursing science' (Vuolanto 2015). Similarly, for feminist and gender studies, we use the term 'gender research', which as an umbrella term which captures the different perspectives of this discipline, field of study, or hybrid approach.

Previous research has investigated the perceptions of the scientifically and experimentally oriented biomedical researchers. However, the health research field is much broader than only biomedicine and clinical science, comprising not only basic medicine, clinical medicine, and medical biotechnology but also including various so-called 'health sciences', such as nursing, nutrition, public and environmental health, and occupational health (The Organisation for Economic Co-operation and Development, OECD 2007). The focus of this article is on nursing research, a health sciences' field that draws from social science and humanities approaches, as well as from biomedicine. Research inside this domain has been both qualitative and quantitative, using methods transferred both from the social sciences and humanities and from the biomedical framework (Yarcheski and Mahon 2013). Thus, nursing research offers a platform from which to study the integration of social sciences and humanities in a domain that is different from previous research.

This article analyses the relationship between nursing research and gender research through an empirical analysis of nearly 200 abstracts of nursing research articles. The abstracts regard gender research positively, demonstrate the tensions in the relationship, and discuss the views and reasons that generate scepticism towards gender research in nursing research. 0 ur article thus provides new knowledge on the diversity of the health research field with regard to its relationship with the social sciences and humanities.

\section{$\mathrm{N}$ ursing research in an international and interdisciplinary context}

Although nursing in many countries has been upgraded to higher education and nursing has become a university-level subject and discipline (Spitzer and Perrenoud 2006a, 2006b), its research has been reported to have difficulties in finding its voice within academia (Meerabeau 2005; see also Heggen, Karseth, and Kyvik [2010] for research-based knowledge production in disciplines such as nursing outside the university sector in what are called the universities of applied sciences or polytechnics). It has been concluded that the young and emerging discipline has relatively low symbolic capital compared with established disciplines, such as medicine (e.g. Grindle and D allat 2000; Meerabeau 2005; Timmons et al. 2015). Meerabeau (2006, 67-68) states that nursing lacks the social capital of medicine and that the curriculum is subject to greater government intervention than that of medicine, resulting in the former being squeezed between governmental forces, work-related claims, and academic demands. 
Nursing research is often situated in administrative structures together with natural and biomedical sciences traditions, whereas with regard to methodologies and theoretical backgrounds, it is closer to the social and human sciences traditions (Northrup et al. 2004, 60). This means adapting to many different disciplinary worlds and identities. The fact that many universities place nursing research in the faculty of medicine speaks of the physicians' desire to act as a 'big brother' and to supervise the academic efforts of the nursing profession (Laiho 2012). What is more, nursing is, by any measure, a female-prevalent discipline, which adds to its low status. Women's exclusion from positions of authority in academia has been well documented (e.g. Morley 2010; Savigny 2014). Meerabeau (2005, 126-130) argues that the gendering of both nursing and academia has had a double impact on the development of nursing education and research.

Interdisciplinarity is a much-discussed topic in nursing research (e.g. Fealy and McNamara 2015, Larson et al. 2011). Some of the discussion also concerns the relationships between professionals rather than only those between academic disciplines (e.g. Chan et al. 2009). However, very few studies have examined interdisciplinarity in nursing journals. In a longitudinal analysis of three major joumals of nursing ( $\mathrm{N}$ ursing Research, W estern Journal of N ursing R esearch, and Journal of A dvanoed N ursing) from 1990-2010, Y archeski and Mahon (2013) investigated interdisciplinarity in quantitative nursing research articles. They found that research has been increasingly conducted in multidisciplinary teams over the years. Psychology, medicine, and statistics were the most represented as co-authors of nursing research articles. Closer to 2010, nursing research was increasingly allied with medicine. Theoretical orientations were found to be adopted primarily from psychology and secondarily from sociology. This research, although limited to three journals, draws a picture of nursing research as increasingly interdisciplinary and, to some extent, also a collaborator of the social sciences.

Some studies have been conducted on the influence of gender research on other fields and disciplines (e.g. Beddoes and Borrego 2011; Strathern 1987), as well as on nursing research (e.g. Bunting and Campbell 1990; Meerabeau 2005; and Riley 1999). Bunting and Campbell (1990) have studied the relationship between feminism and nursing from a historical perspective, and they found that, historically, feminism and nursing have not been interrelated. In this article, we aim to paint a comprehensive picture of the relationship between nursing research and gender research as articulated in intemational nursing research articles. Within the international nursing scholars' community, the gender perspective has been a matter of debate for decades; however, the actual contents of the relationship and the use of gender research in nursing are rarely examined.

\section{Theoretical framework}

This article belongs to research on interdisciplinarity (see Frodeman 2010; Trowler 2012). We understand interdisciplinarity as aiming at integrating data, methods, tools, concepts, and theories from different disciplines in order to create a common understanding of an issue as separate from multi- or transdisciplinarity (for definitions, see Bruun et al. 2005; Huutoniemi 2012; Petts et al. 2008; and Frodeman 2010). The article is particularly grounded in studies about the integration of the social sciences into the health research field (Segal, 2007; Albert et al. 2008, 2009; Prainsack et al. 2010; MacMynowski 2007; Brown 2013; and Currie et al. 2014). This literature concludes that the integration of the social sciences with biomedical research is anything but simple. On the contrary, the research points out the various difficulties and the uneasy reception of the social sciences in biomedical research. Namely, researchers have argued that the interdisciplinary relations within the health research field may be hampered by the tendency of medical researchers to value biomedical research over other research traditions (Segal, 2007, 11). For example, Albert et al. (2009, 181-182) argue that the issue may appear when medical researchers expect social science research procedures to meet the criteria of objective evidence in medical research and to use methodological tools such as 'purposive sampling' and 'triangulation' as indicators of scientific quality. Prainsack et al. $(2010,283)$ point out the epistemological differences that make it difficult to collaborate because social scientists seek to 'describe and understand', 
whereas biomedicalists aim 'to improve health care and cure diseases'. Previous research also points out that there are different layers of power associated with different disciplines, which has an effect on interdisciplinary collaboration (MacMynowski 2007). In particular, Albert et al. $(2009,190)$ show that power associated with medical research very likely forms an obstacle to social scientists' entrance to health research.

Conscious of these tensions between social scientists and biomedicalists, we focus on the integration of gender research into nursing research. O ur starting point is McNamara and Fealy's (2014, 164; quoting Nelson and Gordon 2006) description: "The overarching narrative of "nursing science" is one of caring, the privileging of patients' and nurses' lived experiences of health, illness and healthcare, and a focus on subjectivities and interpersonal relationships between individual nurses and patients'. This narrative of the nursing field is, in our view, close to the narrative of gender research which has emphasised and called for the turning of all disciplines towards the 'personal': subjectivity; the experiences of marginalised groups, such as women and ethnic and sexual minorities; and the relationships between individuals (Stacey and Thorne 1985). Moreover, within this methodological turn to the personal is also inscribed an agenda or idea of feminist scholarship offering 'the promise of a common ground between disciplines' or the idea that 'feminist insights might modify work' in other disciplines (Strathern 1987, 276), or that this turn to the personal could be transferred to other disciplines as well. We recognise that the relationship between the two disciplines of nursing research and gender research, coming from such different disciplinary traditions, might be affected by the general weak acceptance and reception of the social sciences in medical and health research. However, despite and indeed because of this tension, we are interested in how the relationship between these two is still depicted as possible- and, to some extent, even desirable- within nursing research.

Our study draws its theoretical insights from research within the sociology of science. It uses ideas about the intertwining of power and knowledge emphasised especially in the works of Pierre Bourdieu (1975, 1988; also Albert and Kleinman 2011). In these works, the academic community, comprising various disciplines, is seen as a field of struggle for recognition and authority. Bourdieu highlighted the hierarchy between disciplines and their consequent prestige, legitimation, and academic value. Some disciplines hold or are given low levels of symbolic capital and some high; some disciplines are seen to have lower importance and less scientific authority than others. Consequently, all disciplines are not on the same level; instead, some acquire a reputation as subordinate and some as dominant within the academy. Bourdieu also points out the hierarchies between different methodologies, which occasionally manifest in placing experimental sciences at the top and qualitative methods at the bottom.

The inspiration from Bourdieu's works is important for this article as we focus on domains such as nursing research and gender research, which have been considered to hold low symbolic capital and authority. For example, in the British context, nursing research is argued to have a low academic status due to its professional-vocational background, the prevalence of female and mature students, its small size, and the weak female voice in the academy (Meerabeau 2005; Findlow 2012; Thompson 2009; in Finland, see Vuolanto 2015, 2016). In the case of gender research, the discipline is seen to have a vulnerable academic status due to its being political, interdisciplinary, and small in size. As in nursing research, in gender research, the majority of the researchers, staff, and students are women ( $\mathrm{G}$ riffin 2009; Hemmings 2011; and Pereira 2012a, 2012b). This article seeks to pay attention to the gendered relations of power interwoven with other power structures in epistemic cultures, as gender research and nursing research appear to share an ambivalent and gendered relationship with the discipline with which they are organisationally most often coupled. Skeggs (2008) argues that gender research has a 'dirty' history with sociology, in that some sociologists continue to be 'blind to the fact that women exist, and/ or have value'; Meerabeau (2005) highlights the invisibility and inaudibility of female nursing research alongside the more masculine-coded medicine. The research question posed in this article is this: In what ways has the 
relationship between nursing research and gender research been articulated in the abstracts of nursing research articles?

\section{Research material and methods}

L iterature search proeedure

We aimed to find the broadest possible dataset and longest possible timeframe for the analysis in order to investigate the international discussion covering the relationship between nursing research and gender research. The Scopus database was selected because it covers nursing research broadly, comprising approximately 6,800 journals in health research, and because it allows for an analysis of the abstracts of a large number of articles. Separate searches were conducted using short and long versions of 'nursing research', 'nursing science', and 'nursing' as search terms on the nursing research side and 'gender research', 'gender studies', 'women's studies', and 'feminism' on the gender research side. Finally, the different keywords were combined into one search term. ${ }^{1}$ These terms were searched in the abstract, article title, and keywords, as allowed by the Scopus database. With these search terms, 478 articles were found. D ue to the unavailability of abstracts or the focus on issues not relevant to the article, only 180 abstracts were chosen. By taking into account overlapping abstracts and by narrowing down to the most relevant ones, a total of 180 abstracts for nursing research articles from the years 1987 to 2015 were taken under closer scrutiny. For example, abstracts in which gender was introduced as a variable and which compared females and males without any problematisation were excluded. Some of the articles, particularly the older ones, were not included due to the unavailability of an abstract.

\section{Research material}

The analysis is focused on the abstracts of research articles. This strategy was chosen because our aim was to preliminarily scan as many articles as possible in many different publication forums. Some examples of work that used full articles went more deeply into the literature references and citation context, with a substantially smaller number of articles on fewer publication forums; this was not our idea in this article (Beddoes and Borrego 2011; Brodin D anell 2012). The 180 selected abstracts represent research articles that argue in some way about the relationship between nursing research and gender research. The scope (28 years) of our study is long; the first abstract dates to the year 1987 and the latest to the year 2015. Most of the abstracts $(n=113)$ have been published since the 2000s, and 32 abstracts were published in the 2010s.

The Scopus database provides information about the affiliations of all the authors of an article. In cases of uncertainty, the author affiliations were double-checked in the database by searching the author by name. It is our general impression that most of the authors were women. However, some of the journals provide only the initials of the author; therefore, the gender of these authors could not be analysed thoroughly. A clear majority of the authors came from North-American affiliations. The USA hosted the affiliation of authors in 73 articles and Canada in 48 articles. Twenty-one Australian and 15 British writers were also represented in the research material. It is surprising that so few European countries were involved in the material (A ustria, G ermany, Estonia, Sweden, Spain, and Ireland all had one article each). Nine articles originated from A sia (South Korea, Taiwan, Japan, and Korea) and 11 articles from South America (Brazil and Chile). Two authors had their affiliation in Africa (South Africa and Nigeria). Three scholars in our material had written several abstracts. Nursing research professor Eun-O k Im (USA) had nine articles within the sample of abstracts. Professor emerita Joan Anderson (Canada) and research professor Nel Glass (Australia), both of whom have an educational background in sociology and have been professors in nursing, were the authors of five articles.

1 (TITLE-ABS-KEY ( feminis* OR 'feminism' OR 'feminist studies' AND 'nursing research' ) ) OR ( TITLE-ABSKEY ( feminis* AND 'nursing science' ) ) OR ( TITLE-ABS-KEY ( 'gender studies' AND 'nursing research' OR 'nursing science' ) ) OR ( TITLE-ABS-KEY ( 'gender' AND 'nursing research' OR 'nursing science' ) OR ( TITLE-ABSKEY ( 'women's studies' ) AND (TITLE-ABS-KEY ( 'nursing research' ) ). 
Most of the analysed abstracts originated from A dvances in N ursing Science $(\mathrm{n}=38)$ and Journal of A dvanced $\mathrm{N}$ ursing $(\mathrm{n}=21)$. A dvances in $\mathrm{N}$ ursing Science is based in the United States and is published by the American Wolters Kluwer Health. Journal of A dvanœe $\mathrm{N}$ ursing is an international peer-reviewed journal published by Wiley; the editorial board is mostly but not exclusively based in the United Kingdom (UK). Both of these are strongly focused on nursing research and have high impact factors compared to other journals in the field. They are also among the largest nursing research journals, issuing several times a year.

We recognise the limitations of our research material. Scopus mostly covers an Anglo-American context, with English as the main language of the articles found. Additionally, disciplines are always shaped by their national, organisational, and institutional contexts, as well as professional practices and traditions. In this research, we are not able to analyse how these aspects affect the links between nursing research and gender research, as national differences could not be identified through our research material. However, the abstracts found in Scopus are here seen as a representative sample of the discussion, which can act as a preliminary starting point for more in-depth analyses of nursing research in different national contexts.

A nalysis

The abstracts were first read through and preliminarily coded by both authors. This close reading of the abstracts, inspired by rhetorical discourse analysis (Segal 2009; Fahnestock 2009), was guided by the following questions: What did the abstracts imply about the relationship between gender research and nursing research? How was gender research articulated in the nursing research abstracts? How did nursing research build its own identity in relation to gender research? How was the gender perspective justified in nursing research?

At this stage, four codes were found: 1) Feminist and gender studies help to highlight the socio-political context in nursing research; 2) Feminist and gender studies develop or reform the nursing research tradition; 3) Nursing research may contribute to feminist and gender studies or social research; and 4) There is resistance to feminism inside nursing research, in addition to sexual bias and gender role stereotypes. These codes were negotiated between the authors and used for the second round of reading. In the second round, the first author coded the abstracts according to these four codes, after which the second author checked the coding and made remarks. The final three discourses were then decided: the first discourse consisted of the initial first code, and the second discourse clustered the initial second and third codes. The frequent critique in the abstracts was used to form the third discourse, which also included the initial fourth code. The three discourses were found to be the most common and most clearly representative across the abstracts.

The second round of analysis also included the expressions of the abstracts listed under each code. These listed expressions were clustered under the titles when forming the three discourses. It must be emphasised that one abstract could belong to many discourses; thus, the total number of expressions (273) is not the same as the number of abstracts (180). In total, $21 \%$ of the abstracts included more than one discourse. In Table 1, we present the three discourses by year. 
Table 1. D iscourses by year (number of expressions and the percentage from all expressions).

\begin{tabular}{|l|c|c|c|c|c|}
\hline Discourse & $\mathbf{- 1 9 9 0}$ & $\mathbf{1 9 9 1 - 2 0 0 0}$ & $\mathbf{2 0 0 1 - 2 0 1 0}$ & $\mathbf{2 0 1 1 -}$ & Total \\
\hline $\begin{array}{l}\text { G ender research } \\
\text { helps to highlight } \\
\text { the socio-political } \\
\text { context in } \\
\text { nursing research }\end{array}$ & $0(0 \%)$ & $24(27 \%)$ & $49(55 \%)$ & $16(18 \%)$ & $89(33 \%)$ \\
\hline $\begin{array}{l}\text { G ender research } \\
\text { develops or } \\
\text { reforms the } \\
\text { nursing research } \\
\text { tradition }\end{array}$ & $3(3 \%)$ & $30(34 \%)$ & $36(41 \%)$ & $19(22 \%)$ & $88(32 \%)$ \\
\hline $\begin{array}{l}\text { G ender research } \\
\text { ex ists as a form } \\
\text { of critique within } \\
\text { nursing research }\end{array}$ & $11(12 \%)$ & $42(44 \%)$ & $34(35 \%)$ & $9(9 \%)$ & $96(35 \%)$ \\
\hline
\end{tabular}

We found three distinct but also overlapping discourses: $G$ ender research helps to highlight the socio-political context in nursing research; $G$ ender research develops or reforms the nursing research tradition; and $G$ ender research ex ists as a form of critique inside nursing research. We also intended to study what gender research frameworks were emphasised in the abstracts. We encoded gender research perspectives on the basis of the presented descriptions in the abstracts. However, not many abstracts expressed this explicitly. This and the lack of references to the theoretical literature in the abstracts made an analysis of gender research approaches impossible, in contrast to such detail as in Beddoes and Borrego (2011), who analysed the engagement of engineering education with different traditions of feminist theory.

We observed some patterns in how gender research was framed. We found no clear gender research perspectives manifested temporally or linked to a certain discourse. The majority of abstracts emphasised feminist critiques, highlighted women and different marginal groups, and challenged existing power structures in addition to calling for gender awareness. When analysing the explicitly indicated theoretical frameworks voiced by the abstracts, postcolonial feminism and associated theories $(\mathrm{n}=14)$ were brought up most often. All references to postcolonialism originated in the 2000s. Marxist feminism, poststructuralist feminist theory, and liberal and socialist feminist theory received single mentions. Furthermore, the male perspective and masculinity came up mainly from the 2000s onwards.

\section{Gender perspective in intemational nursing research articles}

\section{Gender research helps to highlight the socio-political context in nursing research}

A very common way of articulating the relationship between nursing research and gender research is to argue that gender research can help in understanding the cultural context of nursing. $G$ ender research serves as a tool for focusing on race, gender, class, and other social, cultural, political, and economic factors related to care. It is made apparent that gender research offers an analytical lens for understanding how health, social and cultural contexts, race, and gender intersect in nursing practice, unveiling many problematic discriminatory practices, inequalities, and cultural differences.

The abstracts imply that gender research opens up the broad environment in which nursing takes place beyond the level of individual patients or healthcare consumers to the social, cultural, political, and economic factors in healthcare. Gender research is indicated to help nursing researchers understand the broader societal context in this way: 
D rawing on past research, we demonstrate how the postcolonial feminist perspective can be used to illuminate the ways in which race, gender, and class relations influence social, cultural, political, and economic factors, which, in tum, shape the lives of immigrant women. ( 0 'Mahony and Truong D onnelly 2010)

The abstracts argue that gender research enables a highlighting of inequities in society, particularly those caused by healthcare practices. Here, gender research is demonstrated to help nursing research address the needs of marginalised groups and ethnic minorities:

Intersectionality is the multiplicative effect of inequalities experienced by nondominant marginalized groups, for example, ethnic minorities, women, and the poor. The elimination of health disparities necessitates integration of both paradigms in health research. This study provides a practical application of the integration of biomedical and feminist intersectionality paradigms in nursing research, using a psychiatric intervention study with battered Latino women as an example. (Kelly 2009)

The abstracts state that gender research reveals the gender order and existing gender roles both in nursing and society. G ender studies are here understood to highlight gender differences and gender identities relevant to care:

Not considering cancer patients' own views and experience with pain, especially gender and ethnic differences in their cancer pain experience, was reported to be a major contributor to the miscommunication that frequently results in inadequate cancer pain management. The purpose of this study was to explore white cancer patients' perception of gender and ethnic differences in pain experience through an online forum. (Im 2006)

A typical statement in the abstracts is "The findings of this study have implications for nursing research, education, and practice' (Arslanian-Engoren 2000). Thus, the three elements- research, education, and practice - are often intertwined and appear in the same abstract. It is argued that the relationship of nursing research with gender research has implications for nursing education. The abstracts argue that education should be focused on inequities in the classroom and in the domain in which qualified nurses work - that is, nursing practice. The involvement of nursing research with gender research is seen as a means to bring gender sensitivity into practice. The abstracts imply that the relationship with gender research expands the knowledge base of nursing education and helps to highlight the professional orientation of nursing research:

Narrative Pedagogy as sharing and interpreting contemporary narratives is a call for students, teachers, and clinicians to gather and attend to community practices in ways that hold everything open and problematic. It utilizes conventional, phenomenologic, critical, and feminist pedagogies, along with postmodern discourses to revision nursing education. (Diekelmann 2000)

In addition to the effects on nursing education, the abstracts frequently state that recognition of the context of nursing with the help of gender research may have effects on changing nursing practice. The context of academic nursing belongs to nursing education and further training and is, thus, a part of the continuum of the nurse education path. To practice research is, in a way, to legitimate research and education at the same time, and this is seen to add to the academic value of nursing research:

This paper suggested that incorporation of feminist approaches within nursing is a valuable attempt to expand the body of nursing knowledge and to enhance the quality of nursing care services by rectifying male-oriented knowledge and by empowering women in the care of other people as well as themselves. (Yi and Yih 2004)

Under the first discourse, all abstracts attempt to tackle the social inequalities in the nursing domain. The abstracts included in this discourse are filled with emancipatory rhetoric. As Savigny writes about one of the roles of gender research in academia $(2014,798)$ : 'G iving voice to experience is a key mechanism 
through which feminist and critical theories seek to challenge existing power structures. A feminist epistemology seeks to deconstruct the power relations which underpin the production of knowledge.' The abstracts articulate the role of gender research precisely in this way. G ender research is understood to open up the possibilities of promoting social and political change in nursing, health, and, more broadly, society. G ender research is introduced as a change agent to achieve social justice in the healthcare system. The relationship between nursing research and gender research is presented as a powerful alliance that can challenge the current power dynamics and highlight critical questions, such as whose knowledge is visible and whose is suppressed and which are the marginalised groups and neglected subjects.

In this discourse, the abstracts stress that nursing researchers ought to be responsive to social demands for knowledge, for example, from social groups, social movements, and government bodies (Albert and Kleinman 2011, 270). The abstracts indicate that nursing research has a need to open up, to be reflexive, and to include societal and cultural questions in its scope. This is what Elzinga (1990) calls a social legitimation strategy. In this legitimation strategy, gender research is understood to participate in developing more societally relevant nursing research. The abstracts aim to bring to the fore the varied contexts of patients and nursing care. In so doing, the abstracts identify those social groups which can be said to be beneficiaries of nursing research inspired by gender research.

From the Bourdieusian perspective, gender research in the nursing research abstracts is understood to contain valuable symbolic capital which is used to make a change towards more societally relevant nursing research. Thus, the abstracts indicate that gender research includes symbolic capital that nursing research could use for its benefit: Through its engagement with gender research, nursing research is expected to become a stronger player in the 'scientific game' (Albert and K leinman 2011, 269).

\section{Gender research develops or reforms the nursing research tradition}

Another common way of writing about interdisciplinarity in the abstracts is to argue that nursing research - the philosophical framework, concepts, methodology, and methods - can be developed through gender research. The abstracts imply that gender research enables theoretical refinement and conceptual development in the field.

The abstracts promote gender research as a new or additional approach to nursing research, as shown below:

D rawing on newly emergent conceptualizations of suffering in the social sciences that emphasize political dimensions, this article uses a critical-feminist, self-reflective approach to propose a reconceptualization of suffering for nursing science. (G eorges 2004)

In the paper, I suggest that humanistic action research, informed by recent feminist thinking, has potential to produce a more creative and clinically relevant future for nursing research than is currently so. (Johnson 1997)

The abstracts indicate that gender research reforms the theoretical foundations of nursing research by giving tools to understand the values and beliefs (or worldviews) behind different approaches. This is also presented as significant for the ethical considerations in nursing research:

The ethical 'eye' of nursing, that is, the particular moral vision and values inherent in nursing work, is constrained by the preoccupations and practices of the superordinate biomedical structure in which nursing as a practice discipline is embedded. The intimate, situated knowledge of particular persons who construct and attach meaning to their health experience in the presence of and with the active participation of the nurse, is the knowledge that provides the evidence for nurses' ethical decision making. It is largely invisible to all but other nurses. Two nurse researchers, Joan Liaschenko of the University 
of Minnesota and Patricia Rodney of the University of Victoria, have investigated the ethical concerns of practising nurses and noted in their separate enquiries the invisible nature of critical aspects of nursing work. Noting the similarities in their respective observations, and with the feminist ethics of Margaret Urban Walker as a theoretical framework, this article examines the concept of 'invisibility' as it relates to nursing work and nursing ethics. (Bjorklund 2004)

In this vein, the abstracts argue for the empowerment of the qualitative research approach through gender research, as nursing research is centred by administration in medical schools, which are dominated by evidence-based research approaches. Q ualitative research seeks to find an alliance with the social sciences to escape the pressures that the evidence-based research dominance causes.

O verall, this discourse not only generates an impression that nursing research should be changed under the threat of becoming deficient but also creates unity between these two areas of research by presenting the benefits of collaboration. Moreover, it implies, as in the abstract above, that they can join together to change the hierarchical structure between disciplines. The similar beliefs and ideologies between the two are particularly pointed out, as they are seen to offer many possibilities for a beneficial mutual collaboration and to change the hierarchical position of nursing research.

In this discourse, the abstracts tend to connect gender research to the theoretical development of nursing research. Thus, the abstracts participate in what Elzinga (1990) calls a cognitive legitimation strategy. In this strategy, nursing research is enriched and changed by its engagement with gender research. $G$ ender research methodologies are presented as the legitimate features of 'good' scientific practice and help nursing research to become part of 'the legitimate culture of the scientific field' (Albert and Kleinman 2011, 268). Nursing research is presented in the abstracts as joining what is understood to be legitimate research in the scientific field through the inclusion of gender research. This partnership is expected to give nursing research more academic value.

\section{Gender research exists as a form of critique within nursing research}

The underlying but implicit assumption in the abstracts through the first two discourses is that there is a certain need to critique previous nursing research. The need for awareness and a new scope and orientation in nursing practice and research has become evident, and thus the abstracts generate the impression that if gender research perspectives are not included, serious deficiencies in nursing research will remain and its contextualisation will be short-handed. Thus the abstracts implicitly present a form of critique of nursing research.

The third discourse uses gender research as a form of explicit critique inside nursing research. Here gender research is understood to challenge the underlying assumptions in nursing research. Gender research is said to identify the weaknesses of former nursing research and, in this way, to both enable and necessitate a reform of nursing research. The abstracts argue that gender research helps to point out and overcome the limitations of previous nursing research. In this way, the abstracts highlight the existing ignorance of gender analysis and present this ignorance as an error or shortcoming of nursing research that ought to be dealt with. They emphasise the reluctance of nursing research to take gender research under its scope and point out the rarity of gender perspectives in nursing and nursing research, such as in the following abstracts:

It was concluded that the issue of woman in the third age was investigated in few studies. In addition, those researches' objects was strongly removed from gender issues, demonstrating that sexual approach of ageing was out of consideration, as well as denial of woman's social roles. (Figueiredo and Tyrrel 2005) 
A number of studies on cancer pain have been conducted, but the researchers rarely considered gender and ethnic differences in cancer pain. (Im and Chee 2001)

O ne form of critique is to state that there is gender bias and lack of gender sensitivity in nursing research. This may mean the oversampling of females in nursing research, such as in this abstract:

D ata from 300 studies published in four research journals in 2010-2011 were analyzed to assess whether nurse researchers continue to oversample females. O ne-third of the studies had samples that were $100 \%$ female and, on average, $74 \%$ of all study participants were female. As was found for studies published 5 years earlier, the bias against male participants was consistent across studies differing in methods, specialty areas, funding, and sample characteristics. Studies with male first authors, however, were significantly less likely to have biased samples. A uthors of only $23.6 \%$ of studies with mixed-sex samples provided information about sex differences in outcomes. Because of gender bias, the evidence base for nursing practice may suffer from problems with generalizability. (Polit and Beck 2013)

There are also abstracts that argue that there should be more research on men and male identities in the nursing profession and that nursing research should be developed to address men and masculinities. However, these critiques may also state the opposite- namely that nursing research would be accused of androcentrism or the use of a masculine model of research, which exemplifies another type of gender bias.

Some abstracts argue that nursing research should be more critical of the scientific worldview than it has been. $G$ ender research is promoted as a means to critique the traditional scientific approach, for example, in these abstracts:

Using a variety of perspectives, including feminist theory, they are critiquing many of the basic assumptions about science, scientific method and scientific knowledge. This paper uses sociological and feminist theory to support the idea that nursing, as a discipline, has a distinct knowledge base which is not grounded in empiric-analytic science and its methodology but which stems from the lived experiences of nurses as women and as nurses involved in caring relationships with their clients. (Hagell 1989)

Myths that have become traditional, scientific male-centred methodologies now solidly rooted in the health care community are identified. The author explains that once the myths are identified, they should be extracted and isolated from the context of nursing. This is the way feminist research can be useful. (Gendron 1993)

In this argumentation, gender research is a way to reveal and challenge existing power structures within academia.

As part of the critiquing of former nursing research, the abstracts argue that there are tensions in the relationship between nursing research and gender research. They state that some nurses and nursing scholars resist taking gender research perspectives into account or putting them into wider use. The abstracts make it apparent that previous nursing research and gender research could have had more interaction with each other. This argument appears to aim at making space for the acceptance and wider use of gender research in nursing research.

It must be borne in mind that most of the abstracts studied promote gender research to the nursing researchers, the target audience of the journals. The following abstract exemplifies how the disciplines are presented as separate but maintains that nursing and gender research would benefit from the interaction: 
Despite the fact that the profession of nurse-midwifery and feminism are both disciplines concerned with women and issues affecting women's lives, there has been little investigation or acknowledgment of relationships between their two paradigms. The work presented here is an attempt to discover both similarities and differences between nurse-midwifery and feminist thought. Using a historical approach, it is shown that despite the common goal of improving and maintaining women's status in the world, whether in general or more specifically with regard to health, feminist theorists and nurse-midwives, to a large degree, have worked separately from each other, rarely acknowledging in any formal way the importance of the other discipline. Current issues that have an effect on the practice of nurse-midwifery today- lay midwifery, the profession of nursing, and nurse-midwifery research-are presented in relation to contemporary feminist thought. (McCool and McCool 1989)

In this discourse, gender research is seen to offer a means to critique former nursing research and, as with the other discourses, to develop it further. Thus, gender research is viewed as a form of criticism of the existing nursing research. The abstracts highlight the deficiencies of present nursing research and create an impression that gender research provides one solution and way forward in the development of nursing research. The abstracts may stem from a general dissatisfaction towards the previous nursing research having not included gender research in its agenda. They generate a favourable climate for the inclusion of gender research perspectives into the practices of nursing research and promote the need for criticality.

Following Amsterdamska (2005), we understand that the abstracts perform identity-building for nursing research, as the abstracts target their message at the 'inside' to their fellow nursing scholars. These abstracts participate in self-reflection, an activity that could be called the 'self-evaluation' of nursing research. G ender research acts as a standard for legitimate knowledge-making with which to evaluate the research activities of the field. In the abstracts within this discourse, there seems to be an implicit assumption that 'doing quality work is doing work like theirs' (Albert and Kleinman 2011, 266). This could be called a 'subversion strategy' (Albert and Kleinman 2011, 269), whereby the actors aim to break the current activities of nursing research and create a new hierarchy based on which nursing research would assume a stronger position with the help of gender research.

\section{Discussion and conclusion}

In this article, we analysed the relationship between nursing research and gender research. We found three distinct but also overlapping discourses: $\mathrm{G}$ ender research helps to highlight the socio-political contex $\mathrm{t}$ in nursing research; $G$ ender research develops or reforms the nursing research tradition; and $G$ ender research ex ists as a form of critique inside nursing research. With these discourses, we give a picture of what happens if nursing research is engaged with gender research and how that engagement is understood. Understanding the breadth and depth of the relationship requires further analysis - for example, the theoretical frames that nursing research used and borrowed from gender research-as has been done in the case of engineering education research by Beddoes and Borrego (2011).

In general, the abstracts see gender research as positive for nursing research for both external and internal reasons. Externally, gender research and feminism as a social movement are presented as pressure that comes from the outside. In this, nursing research is understood to become more societally relevant through the relationship with gender research and to address actual social inequities. Internally, or inside the scientific field, nursing research is understood to benefit from gender research and, through it, gain more symbolic capital in relevant academic markets. Gender research is understood to make nursing research stronger both theoretically and methodologically.

The analysed abstracts show a generally positive attitude towards gender research and, at first glance, could be interpreted as a sign of nursing research appearing as more favourable ground than biomedicine 
for the collaboration of health research with social sciences and humanities. The positive attitude may even indicate that gender research and nursing research sometimes already exist as joined fields. However, the positive attitude is also very promotional, meaning that the abstracts aim to promote gender research to nursing research. As such, they are very critical of existing nursing research and may also imply a lack of gender research in the field. This may indicate that there are some individual nursing researchers who push the field towards gender research and see gender research as necessary, but the majority of nursing research remains insensitive to gender research. Therefore, more research is needed to understand the breadth of the relationship between nursing research and this particular social science and humanities field.

There is another critical point to be made about the critique in the nursing research abstracts. In the first two discourses, the critique is implicit and, as such, is not so frankly and openly assessing former nursing research. Thus, the critique in these two discourses is not so censorious, whereas in the third discourse, the critique is, first and foremost, demanding and critical by nature. For nursing research, the established field of medicine - the so-called 'big brother' (Laiho 2012) - is often very close, even for administrative purposes in the same faculty. In this situation, the criticality may be interpreted by nursing scholars as another force against which the activities of nursing research must be legitimated, rather than an ally with which to build up its own identity. The abstracts indicate that the relationship between nursing research and medicine has an effect on the other nursing research relationships. $G$ ender research can also be understood as a force to fight alongside against this power structure in the academic setting. The abstracts promote gender research as a potential companion to nursing research, particularly a theoretical and methodological treasure chest that can help in developing new approaches and becoming more societally relevant. At the same time, however, it is also presented as a possible critical burden or 'thorn in one's side', forcing nursing research to change, which is not always comfortable.

It must be bome in mind that the function of gender research as this kind of critical change agent in the nursing research abstracts analysed here gives only a partial picture of the issue in the broad international context. The sample of 180 abstracts is quite small when it comes to the large numbers of articles published each year in international journals. It might be that the issue is not much discussed overall in fact or, conversely, that we did not reach all the discussions by using the Scopus database, the limitations of which are known (e.g. D ess 2006). The abstracts came mostly from North American ground, specifically the USA and Canada, and, to some extent, from Australia. Very few originated from other parts of the world, such as Europe, South America, Africa, or A sia. These contexts differ greatly from each other. It might be that there are certain pressures, such as ethnic and gender differences, to take into account in some countries more than in others and to discuss in nursing research articles.

This may also stem from the different status of nursing research in different countries, even within Europe (Spitzer and Perrenoud 2006a and b), which may have an effect on the willingness with which the scholars from different countries reflect upon the relationship of nursing research with gender research. For example, although the UK achieved the status of European forerunner in nursing research in the 1970s, the development of nursing as an academic discipline has taken relatively long. Nursing was established in the university system mainly in the 1990s and was connected with the harmonisation of the higher education system when polytechnics were awarded university status in 1992 (Laiho 2012). Thompson (2009; see also Watson 2006; Thompson and Watson 2005) argues that nursing in UK universities is on a shaky ground compared with nursing in universities in the USA, Canada, Australia, and Scandinavia, for example. In the Nordic countries, it appears that although nursing research has been at universities for some 30 years now, the collaboration with gender research is not common. It is a question for further research to analyse the organisational and institutional context that affects the relationship between nursing research and gender research. The project that is already underway as our next focus is about the relationship between nursing research and gender research in the Nordic countries. 
As a whole, our article diversifies the picture of the health research field in general and makes it visible that there are areas within it where the premises of collaboration do not start from the hindrances of collaboration, such as difficulties in finding common language or convergent goals for research. It evinces that in the health research field, there are not only biomedical scientists who are collaborating with social sciences and humanities and shows new dimensions in this collaboration. The idea of integrating the disciplines of nursing research and gender research thus shows a potentially different state of affairs than between biomedicine and social sciences in the former research. The collaboration situation between nursing research and gender research instead demonstrates interdisciplinarity where the collaboration could start with recognising common ground in both disciplines and acknowledging the potential strengths in joint efforts. Instead of starting with hierarchies and differences in research traditions, approaches, and starting points, the integration could start with the power of the strategic alliance: to raise gender awareness through research, to empower ethnic minorities in healthcare as well as society more broadly, or to generate sensitivity in research strategies to different forms of societal inequities.

However, as a subject of research on interdisciplinarity, the relationship between nursing research and gender research is anything but simple. We have here started to explore the situation between these disciplines and can demonstrate that there is indeed collaboration and that it is potentially seen as beneficial (although also critical). But how does this collaboration appear in the real-life situations of researchers, and what are the ways to strengthen it in the future? In addition, it remains to be explored whether nursing researchers and gender researchers have found themselves when doing actual research work-for example, writing funding applications or tackling societal challenges through research. It is also important to monitor whether the collaboration situations between gender researchers and nursing researchers have changed over time and particularly in the times of the so-called 'new governance of science' with diminishing public resources for research and the need to build up alliances with strong players in society and within academia. Thus, instead of closing the issue, our article opens up new windows and questions for interdisciplinarity research to tackle.

\section{References}

Albert, Mathieu and D aniel L. Kleinman. 2011. Bringing Pierre Bourdieu to Science and Technology Studies. Minerva 49(3): 263-273.

Albert, Mathieu, Suzanne Laberge, and Brian D. Hodges. 2009. Boundary-Work in the Health Research Field: Biomedical and Clinician Scientists' Perceptions of Social Science Research. Minerva 47(2): 171- 194.

Albert, Mathieu, Suzanne Laberge, Brian D. Hodges, Glenn Regehr, and Lorelei Lingard. 2008. Biomedical Scientists' Perception of the Social Sciences in Health Research. Social Science \& Medicine 66(12): 2520-2531.

Albert, Mathieu, Elise Paradis, and Ayelet Kuper. 2015. Interdisciplinary promises versus practices in medicine: The decoupled experiences of social sciences and humanities scholars. Social Science \& Medicine 126: 17-25.

Amsterdamska, Olga. 2005. D emarcating Epidemiology. Science, Technology \& Human Values 30(1): 17-51.

Aranda, Kay F. 2006. Postmodern feminist perspectives and nursing research: A passionately interested form of inquiry. Nursing Inquiry 13(2): 135-143.

Arslanian-Engoren, Cynthia M. 2000. G ender and Age Bias in Triage D ecisions. Journal of Emergency Nursing 26(2): 117-124.

Beddoes, Kacey D . and Maura J. Borrego. 2011. Feminist Theory in Three Engineering Education Journals: 1995-2008. Journal of Engineering Education 100(2): 281-303.

Bjorklund, Pamela. 2004. Invisibility, moral knowledge and nursing work in the writings of Joan Liaschenko and Patricia Rodney. Nursing Ethics 11(2): 110-121. 
Bourdieu, Pierre. 1975. The specificity of the scientific field and the social conditions of the progress of reason. Social Science Information 14(6): 19-47.

Bourdieu, Pierre. 1988. Homo Academicus. Cambridge: Polity Press.

Brodin D anell, Jenny-Ann. 2012. Representation and Negotiation of Complementary and Alternative Medicine: A Citation Context Analysis. Science Communication 34(3), 299-333.

Brown, Phil. 2013. Integrating Medicine and Environmental Sociology with Environmental Health: Crossing Boundaries and Building Connections through Advocacy. Journal of Health and Social Behavior 54(2): 145- 164.

Bruun, Henrik, Janne Hukkinen, Katri Huutoniemi, and Julie Thompson Klein. 2005. Promoting Interdisciplinary Research. The Case of the Academy of Finland. Helsinki: Publications of the Academy of Finland 8.

Bunting, Sheila and Jacquelyn Campbell. 1990. Feminism and nursing: Historical perspectives. Advances in Nursing Science 12(4): 11-24.

Chan, Engleangela, S.PM Mei Chi, Shirley Ching, and Syrine K. Lam. 2009. Interprofessional education: the interface of nursing and social work. Journal of Clinical Nursing 19: 168-176.

Currie, G raeme, Nellie El Enany, and Andy G eoffrey Lockett. 2014. Intra-professional dynamics in translational health research: The perspective of social scientists. Social Science \& Medicine 114: 81-88.

D ess, Howard M. 2006. D atabase Reviews and Reports. Scopus. Issues in Science and Technology Librarianship. doi:10.5062/ F4X 0650T

D iekelmann, Nancy L. 2000. Narrative Pedagogy: Heideggerian hermeneutical analyses of lived experiences of students, teachers, and clinicians. Advances in Nursing Science 23(3): 53- 71.

Elzinga, Aant. 1990. The knowledge aspect of professionalization: the case of science-based education in Sweden. In Formation of professions, eds. Rolf Torstendahl and Michael Burrage, 151-173. London: Sage Publications.

Fahnestock, Jeanne. 2009. The Rhetoric of the Natural Sciences. In SAGE Handbook of Rhetorical Studies, eds. Andrea A. Lunsford, Kirt H. Wilson, and Rosa A. Eberly, 175-195. SA G E Publications: Los Angeles, London, New D elhi, Singapore, Washington DC.

Fealy, Gerard M. and Martin S. McNamara. 2015. Transitions and tensions: the discipline of nursing in an interdisciplinary context. Journal of Nursing Management 23(1): 1-3.

Frodeman, Robert (ed.). 2010. The Oxford handbook of interdisciplinarity. Oxford: Oxford University Press.

Figueiredo, Maria L. and Maria A. Tyrrel. 2005. The (in)visible gender of third age in nursing knowledge [O gênero (in)visível da terceira idade no saber da enfermagem.] Revista brasileira de enfermagem 58(3): 330-334.

Findlow, Sally. 2012. Higher Education Change and Professional-A cademic Identity in Newly 'Academic' D isciplines: the Case of Nurse Education. Higher E ducation 63(1): 117-133.

G endron, C. 1993. Feminist strategies in nursing science [Stratégies féministes en science infirmière.]The Canadian nurse 89(5): 41-43.

G eorges, Jane M. 2004. The politics of suffering : Implications for nursing science. Advances in Nursing Science 27(84): 250-256.

G riffin, Gabriele. 2009. The 'Ins' and 'Outs' of Women's/ Gender Studies: a Response to Reports of its Demise in 2008. Women's History Review 18(3): 485-496.

G rindle, Norma and John D allat. 2000. Nurse Education: from casualty to scapegoat? Teaching in Higher education 5(2): 205-218.

Hagell, E.I. 1989. Nursing knowledge: women's knowledge. A sociological perspective. Journal of Advanced Nursing 14(3): 226-233.

Heggen, Kristin, Berit Karseth, and Svein Kyvik. 2010. The relevance of research for the improvement of education and professional practice. In The research mission of higher education institutions outside the university sector, eds. Svein Kyvik and Benedetto Lepori, 45-60. Higher Education Dynamics 31. D ordrecht: Springer. 
Hemmings, Clare. 2011. Why Stories Matter. The Political G rammar of Feminist Theory. D urham \& London: D uke University Press.

Huutoniemi, Katri. 2012. Interdisciplinary Accountability in the Evaluation of Research Proposals. Prospects for Academic Q uality Control A cross D isciplinary Boundaries. Publications of the D epartment of Social Research 17. Helsinki: University of Helsinki.

Im, E unok. 2006. White cancer patients' perception of gender and ethnic differences in pain experience. Cancer Nursing, 29(6), 441-452.

Im, E unok and Wonshik Chee. 2001. A feminist critique of research on cancer pain. Western Journal of Nursing Research 23(7): 726- 752 .

Johnson, Martin B. 1997. Observations on the neglected concept of intervention in nursing research. Journal of Advanced Nursing 25(1): 23-29.

Kelly, Ursula A. 2009. Integrating intersectionality and biomedicine in health disparities research Advances in Nursing Science 32(2): E42-E56.

Larson, Elaine L., Bevin Cohen, Kristine G ebbie, Sarah Clock, and Lisa Saiman. 2011. Interdisciplinary research training in a school of nursing. Nursing Outlook 59(1): 29-36.

Laiho, Anne 2012. The evolving landscape of nursing science in the $2{ }^{1 \text { th }}$ Century - The Finnish case. In Tribes and Territories in the $21^{\text {t }} \mathrm{C}$ entury: Rethink ing the Significance of $\mathrm{D}$ isciplines in $\mathrm{H}$ igher $\mathrm{E}$ ducation, eds. Paul Trowler, Murray Saunders, and Veronica Bamber, 107-117. London: Routledge.

Lamont, Michèle 2009. How Professors Think. Inside the Curious World of Academic Judgment. Cambridge, Massachusetts, London, England: Harvard University Press.

MacMynowski, D ena P. 2007. Pausing at the Brink of Interdisciplinarity: Power and Knowledge at the Meeting of Social and Biophysical Science. Ecology \& Society 12(1): 20.

McCool, William F. and S.J. McCool. 1989. Feminism and nurse-midwifery historical overview and current issues. Journal of Nurse-Midwifery 34(6): 323-334.

McNamara Martin and Gerard Fealy. 2014. Knowledge Matters in Nursing. In: Young M and Muller J (eds.) Knowledge, Expertise and the Professions. London and New York: Routledge.

Meerabeau, Elizabeth., 2006. Poor Relations?: Nursing and Medicine in the English A cademy. Higher Education Q uarterly 60(1): 52-73.

Meerabeau, Liz. 2005. The Invisible (Inaudible) Woman: Nursing in the English A cademy. G ender, Work and Organization 12(2): 124-146.

Morley, Louise. 2014. Lost leaders: women in the global academy. Higher Education Research \& D evelopment 33(1): 114-128.

Nelson Sioban and Suzanne G ordon (eds). 2006. The Complexities of Care. Nursing Reconsidered. New York: Comell University Press.

Northrup, D eborah Thoun, Tschanz, Coby L., Olynyk, Valerie G ., Schick Makaroff, Kara L., Szabo, Joanna, and Biaisio Heather A. 2004. Nursing: Whose D iscipline is it Anyway? Nursing Science Q uarterly 17 (1), 55-62.

OECD 2007. Revised field of science and technology (fos) classification in the Frascati manual. D irectorate for science, technology and industry committee for scientific and echnological policy. Organisation for economic co-operation and development.

O ' Mahony, Joyce Maureen and Tam Truong D onnelly. 2010. Postcolonial feminist perspective inquiry into immigrant women's mental health care experiences. Issues in Mental Health Nursing, 31(7): 440- 449.

Pereira, Maria do Mar. 2012a. 'Feminist Theory is Proper Knowledge, But?...': The Status of Feminist Scholarship in the A cademy. Feminist Theory 13(3): 283-303.

Pereira, Maria do Mar. 2012b. Negotiating the Status of Knowledge in Changing A cademic O rganisations: The Paradoxical Case of Women's and G ender Studies. In Proceedings from G EX cel Theme 11-12: G ender Paradoxes in Changing Academic and Scientific O rganisation(s), eds. Sofia Stird, Liisa Husu, and Lena G unnarsson, 113-122. GEX cel Work in Progress Report Volume X. Tema G enus Report Series 14. Linköping: Linköping University. 
Petts, Judith, Susan O wens, and Harriet Bulkeley. 2008. Crossing Boundaries: Interdisciplinarity in the Context of Urban Environments. G eoforum 39: 593-601.

Polit, D enise F. and Cheryl T.A. Beck. 2013. Is there still gender bias in nursing research? An update. Research in Nursing and Health 36(1): 75-83.

Prainsack, Barbara, Mette N. Svendsen, Lene Koch, and Kathryn Ehrich. 2010. How D o We Collaborate? Social Science Researchers' Experience of Multidisciplinarity in Biomedical Settings. BioSocieties 5(2): 278-286.

Riley, Nancy E. 1999. Challenging D emography: Contributions from Feminist Theory. Sociological Forum 14(3): 369-397.

Savigny, Heather. 2014. Women know your limits: cultural sexism in academia. Gender and Education 26(7): 794-809.

Segal, Judy Z. 2007. Interdisciplinarity and Postdisciplinarity in Health Research in Canada. In: Raoul, V., Connie Canam, C., Henderson, A., Paterson, C. (Eds.), Unfitting Stories. Narrative Approaches to D isease, D isability, and Trauma. Wilfried Laurier University Press, Waterloo, Ontario Canada, pp. 11-22.

Segal, Judy Z. 2009. Rhetoric of Health and Medicine. In Andrea A. Lunsford, Kirt H. Wilson \& Rosa A. Eberly (eds.) In The SAGE Handbook of Rhetorical Studies. SAGE Publications, Los Angeles, London, New D elhi, Singapore, Washington DC, 227-245.

Skeggs, Beverley., 2008. The D irty History of Feminism and Sociology: Or the War of Conceptual Attrition. The Sociological Review 56(4), 670-690.

Spitzer, A., Perrenoud, B., 2006a. Reforms in Nursing Education Across Western Europe: Implementation Processes and Current Status. Journal of Professional Nursing 22 (3), 162- 171.

Spitzer, A., Perrenoud, B., 2006b. Reforms in Nursing Education Across Western Europe: From Agenda to Practice. Journal of Professional Nursing 22(3), 150-161.

Stacey, Judith and Thorne, Barry. 1985. The Missing Feminist Revolution in Sociology. Social Problems 32(4), 301-6.

Strathern, Marilyn., 1987. An awkward relationship: the case of feminism and anthropology. Signs 12 (2), 276- 292.

Thompson, D . R., 2009. Is nursing viable as an academic discipline? Nurse Education Today 29, (7), 694- 697.

Thompson, R., R. Watson. 2005. “Editorial: The State of Nursing in the United Kingdom.” Journal of Clinical Nursing 14(9), 1039-1040.

Timmons, S., Edgley, A., Meal, A., Narayanasamy, A., 2015. Being human: Transdisciplinarity in nursing. Journal of Further and Higher Education, http:/ / www.tandfonline.com/ doi/ abs/ 10.1080/ 0309877X.2014.984601\#.V csoaO D V020(acce ssed 11.02.15.).

Trowler, Peter. 2012. D isciplines and Interdisciplinarity. Conceptual G roundwork. In: P. Trowler, M. Saunders, V. Bamber (eds.), Tribes and Territories in the $21^{\text {st }}$ Century. Rethinking the significance of disciplines in higher education. London and New York: Routledge, 5-29.

Vuolanto, Pia. 2015. Boundary work and Power in the Controversy over Therapeutic Touch in Finnish Nursing Science. Minerva Review of Science, Learning and Policy 53(4), 359-380.

Vuolanto, Pia. 2016. A cademic nursing: An Epitome of a Conflict-Prone D omain. Teoksessa Leah G ruenpeter Gold \& G iovanni Scarafile (eds.) Paradox es of C onflicts. Switzerland: Springer, 109122. (Logic, Argumentation \& Reasoning 12).

Watson, R., 2006. "Is There a Role for Higher Education in Preparing Nurses?" Nurse Education Today 26(8), 622-626.

Yarcheski, A., Mahon, N. E., 2013. Characteristics of Q uantitative Nursing Research from 1990 to 2010. Journal of Nursing Scholarship 45 (4), 405-411.

Yi, M., Y ih, B.S., 2004. Feminism and qualitative nursing research. Taehan Kanho Hakhoe chi, 34(3), 565- 575. 